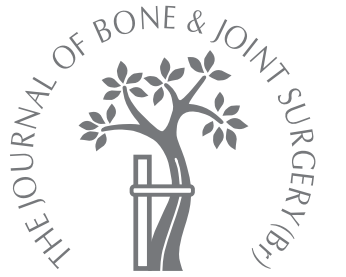

D. J. Deehan,

K. Bell,

A. W. McCaskie

From Freeman

Hospital and

Newcastle United

Football Club

Academy, Newcastle, England

\title{
ANNOTATION
}

\section{Adolescent musculoskeletal injuries in a football academy}

\begin{abstract}
Interest in football continues to increase, with ever younger age groups participating at a competitive level. Football academies have sprung up under the umbrella of professional clubs in an attempt to nurture and develop such talent in a safe manner. However, increased participation predisposes the immature skeleton to injury. Over a five-year period we have prospectively collected data concerning all injuries presenting to the medical team at Newcastle United football academy. We identified 685 injuries in our cohort of 210 players with a mean age of 13.5 years ( 9 to 18$)$. The majority of injuries $(542 ; 79 \%)$ were to the lower limb. A total of $\mathbf{2 0}$ surgical procedures were performed. Contact injuries accounted for $31 \%(210)$ of all injuries and non-contact for $69 \%(475)$. The peaks of injury occurred in early September and March. The 15- and 16-year-old age group appeared most at risk, independent of hours of participation. Strategies to minimise injury may be applicable in both the academy setting and the wider general community.
\end{abstract}

Football is the national sport of the United Kingdom. It is played by both males and females and across all cultural divides. It attracts many participants and remains very popular as a spectator sport. In the professional game in England, the incidence of significant injury is approximately 1.3 per person per season, resulting in a mean loss of 22 days (SD 33.6) of training and competition per annum. ${ }^{1}$ An increase in media coverage has resulted in an enormous investment from commercial organisations including exclusive television rights. Recently, the live television rights to the English Premiership were sold for a record $£ 1.7$ billion. ${ }^{2}$ Success on the pitch is often met with generous financial reward.

There are a number of potential avenues through which a young person can pursue a career in football. In an attempt to nurture junior talent the majority of teams in the Premier League have developed football academies. The objective of the Football Association (FA) Programme for Excellence is to identify players of outstanding ability and place them in a technical and educational programme designed to develop their football skills in conjunction with their personal education. The Football Foundation, a partnership funded by the FA Premier League, the FA and the Government has been created, with the mission to improve facilities, create opportunities and build communities. It continues to revolutionise participation in the game at grass roots level and has seen over $£ 120$ million invested. ${ }^{3}$ Football academies operate at every age level, from under 9 years of age to under 18 years.

The Newcastle United Football Club (NUFC) academy was founded in 1998 and has an annual intake of approximately 15 boys between the ages of 14 and 16 years. It allows for full-time in-house teaching of the national educational curriculum, as well as creating the environment to develop football skills to a professional level through coaching, training and engagement in organised league games nationally. A second, larger group of players attend for teaching and football coaching, although the children go to a local school. The academy has a staff of full-time physiotherapists, coaches, a family liaison worker and a sports physician. The FA guidelines require all entrants to have cardiac and orthopaedic screening (FA medical screening programme). ${ }^{4}$ Such regular high-level activity is not without risk and may predispose the immature skeleton to repeated high forces, with the attendant risk of injury. A previous study has examined a two-year analysis of several academies. ${ }^{5}$ We undertook an audit to investigate the relative risk of injury in relation to duration of exposure over a fiveyear period in a group of adolescents.

As sport is becoming more popular in the wider community, earlier and often more 


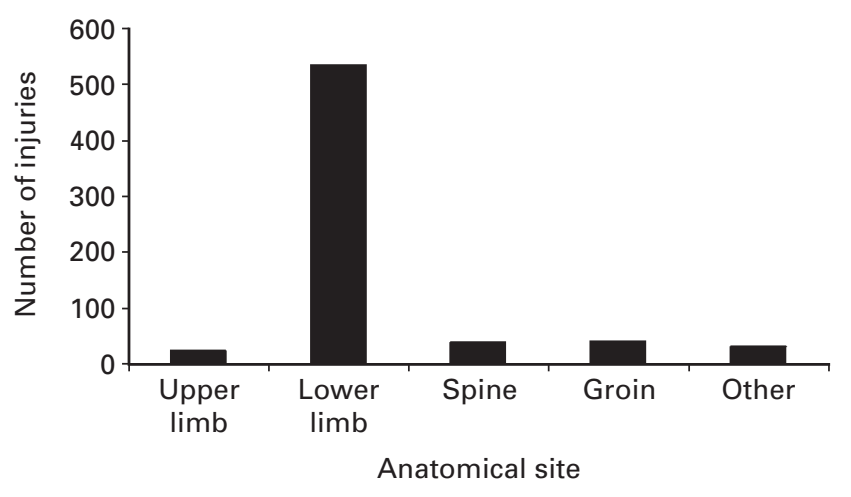

Fig. 1

Total number of injuries per anatomical site.

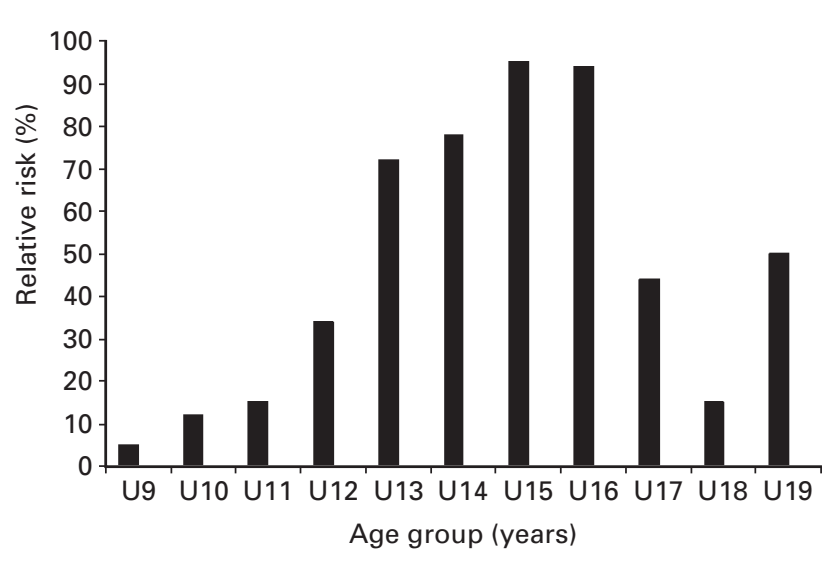

Fig. 2

Relative risk of injury per age group (U, under).

intense participation in the absence of appropriate training and warm-up may explain the increased numbers of children presenting to orthopaedic surgeons with injury. We describe key epidemiological data and highlight potential modes of injury and its prevention.

\section{Patients and Methods}

Details of injuries to players were collected prospectively by the physiotherapy service at NUFC from January 1999 to the present. The complete seasons between August 1999 and July 2004 were used for the purpose of analysis. Over the five-year period, a total of 210 players, with a mean age of 13.5 years ( 9 to 18 ) attended the academy, and all were included in the analysis of the data. All players and/or parents provided consent for storage of the data. Complete anonymity was ensured. All data were stored on an Excel spreadsheet (Microsoft Ltd, Reading, United Kingdom). The categories included details of player demographics, injuries, the classification of injury, supplementary informa-

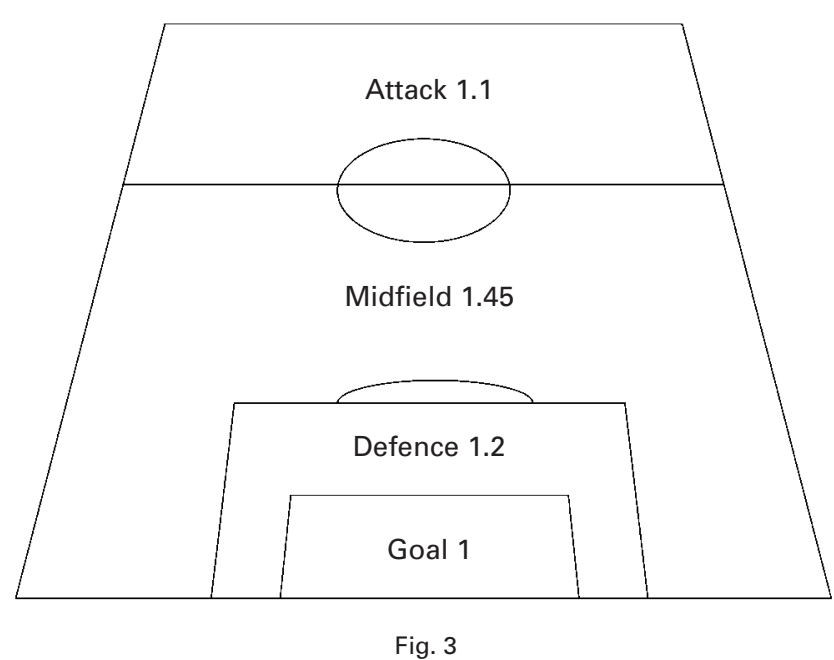

Risk of injury per position on the field relative to the goalkeeper.

tion, and return from injury. For the purpose of the audit, a recordable injury was defined as one that prevented the participant from training or playing for more than 48 hours. Injuries that occurred outside the academy were not included, irrespective of severity. This included medical illness.

\section{Results}

We identified a total of 685 injuires in the 210 players over the five-year period. There were 27 injuries $(4 \%)$ to the upper limb, $42(6 \%)$ to the spine, $44(6.5 \%)$ to the groin, $542(79 \%)$, to the lower limb and $30(4.5 \%)$ to other parts of the body (Fig. 1). Table I shows the sub-division of the injuries to the lower limb.

The majority of injuries $(526,76.7 \%)$ were soft-tissue injuries. Specifically, there were $252(37 \%)$ strains, 121 (18\%) sprains, $40(5.8 \%)$ muscular contusions, 41 (5.9\%) acute tendonopathies, $18(2.6 \%)$ episodes of Sever's disease, ${ }^{6} 31(4.5 \%)$ cases of tissue bruising and $23(3.3 \%)$ examples of Osgood-Schlatter's. ${ }^{7}$

The overall incidence of injury was 0.6 per player, per season.

Figure 2 shows the relative risk of injury per age group. This is expressed as the ratio of the number of injuries per age group, divided by the number of children in the group $\times$ the hours of participation per week. It peaks in the under 15 - to under 16-years age groups.

Figure 3 shows the relative risk per position (the ratio of the total number of injuries per season for that position, divided by the ratio of number of players playing in that position relative to the total number in the squad) with the goalkeeper being allocated arbitrarily the number 1 . It can be seen that the risk of injury is greatest for the midfield area. 
Figure 4 shows the mean number of injuries per month during the five-year period for all participants in the academy. It can be seen that the peaks of injury occur during the early parts of the season in September, and in March.

A total of 351 injuries $(51 \%)$ were sustained during a competitive match, and 334 (49\%) during training or a practice session. We also found that the tackler was as likely to suffer injury as the player being tackled, as $62(9 \%)$ of the total injuries occurred while tackling and $70(10 \%)$ while being tackled. There were 210 (31\%) contact injuries and $475(69 \%)$ non-contact.

A total of 20 surgical procedures were carried out during the five-year period including meniscectomy in six players, manipulation under anaesthetic for nasal fracture in four, inguinal hernia repair in three, open reduction and internal fixation (ORIF) of an ankle fracture in two, excision of an accessory navicular in two, ORIF of a patellar fracture in one and of a forearm fracture in one, and excision of a patellar ossicle in one. In addition, one player suffered a cardiac arrest during a competitive match. He was successfully resuscitated and later had a pacemaker fitted for AV nodal disease.

\section{Discussion}

We have reported musculoskeletal injury in a unique population of 'at-risk' young athletes who participate in regular training, specific exercises and football matches. Such a football academy must meet strict criteria encompassing medical cover, parent liaison, technical facilities, insurance, the maximum number of players per year, and child protection. Each is subject to regular external monitoring by the FA. ${ }^{4}$ We were reassured by the low incidence of injury of 0.6 injuries per player per season.

There is a cyclical pattern to injury which is related to the level of exposure. The peaks seen in the pre-season period and in March suggest that a return to high-impact exercise in unconditioned limbs exposes the individual to injury. Injuries occurred with equal frequency in competitive and practice sessions, perhaps reflecting the high incidence of non-contact injuries. There was no progressive discernible change in the overall incidence of injury per year during the period analysed. Similar incidences and patterns of injury occurred during each of the five years of prospective data collection.

There is a similar likelihood of injury in all positions except midfield, which is to be expected as these players cover the most ground during a competitive game. We were also intrigued to discover that the tackler was as likely to suffer a significant injury as the person being tackled. More than three-quarters of all injuries $(79 \%)$ involved the lower limb, reflecting the nature of the sport. Injuries to the upper limb were usually secondary to a fall or catching a ball.

During the period, 20 surgical procedures were required on the musculoskeletal system and one player had to withdraw from further participation on a permanent basis. We had one instance of cardiac arrest during a competitive
Table I. Anatomical location of injury by region

\begin{tabular}{|c|c|c|}
\hline Region & Detail & Number $(\%)$ \\
\hline \multirow[t]{5}{*}{ Thigh } & Adductors & $57(27)$ \\
\hline & Iliotibial band & $5(2)$ \\
\hline & Quadriceps & $77(36)$ \\
\hline & Hamstrings & $72(35)$ \\
\hline & Total & $211(100)$ \\
\hline \multirow[t]{10}{*}{ Knee } & Anterior knee pain & $9(9)$ \\
\hline & Soft-tissue inflammation & $19(19)$ \\
\hline & Chondral lesion & $2(2)$ \\
\hline & Cut & $2(2)$ \\
\hline & Meniscal injury & $8(8)$ \\
\hline & Osgood-Schlatter ${ }^{7}$ & $21(20)$ \\
\hline & Periostitis & $2(2)$ \\
\hline & Sprain of the medial collateral ligament & $32(31)$ \\
\hline & Patellar tendinitis & $7(7)$ \\
\hline & Total & $102(100)$ \\
\hline \multirow[t]{8}{*}{ Ankle } & Capsular tear & $6(5)$ \\
\hline & Chondral lesion & $5(4)$ \\
\hline & Fracture of the fibula & $1(1)$ \\
\hline & Soft tissue & $12(10)$ \\
\hline & Sever's ${ }^{6}$ & $16(13)$ \\
\hline & Sprain of the anterior talofibular ligament & $72(58)$ \\
\hline & Tendinitis & $11(9)$ \\
\hline & Total & $123(100)$ \\
\hline \multirow[t]{4}{*}{ Foot } & Left midfoot & $14(34)$ \\
\hline & Right midfoot & $22(52)$ \\
\hline & Forefoot & $6(14)$ \\
\hline & Total & $42(100)$ \\
\hline Other & & 64 \\
\hline
\end{tabular}

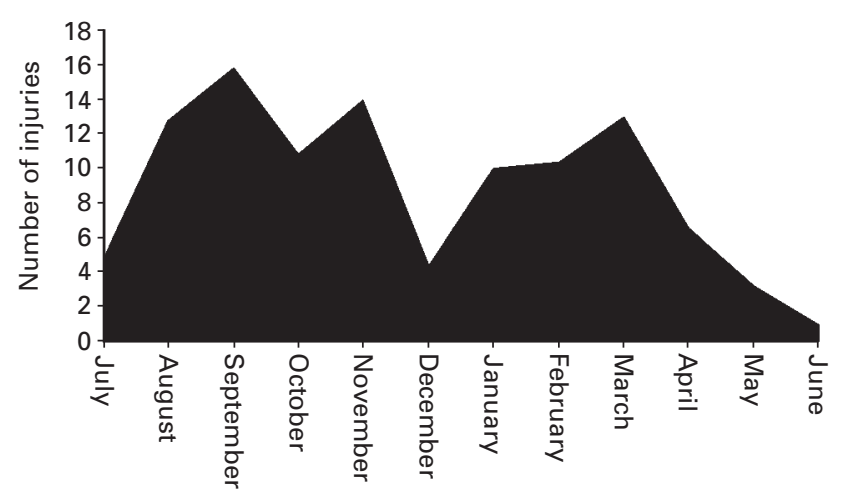

Fig. 4

Mean number of injuries per month over a five-year period for all children in the academy.

game. The player was successfully resuscitated, with no long-term harm.

The prevention, early diagnosis and treatment of significant sporting injury in the younger patient aims to minimise long-term functional impairment. ${ }^{8}$ The prevention of injury or further injury is crucial to minimising problems with longer-term degenerative joint disease and persistent dysfunction in this young age group. ${ }^{9}$ We are aware of a limited number of knee injury prevention programmes practised in the USA which are designed to reduce injuries 
to the anterior cruciate ligament through neuromuscular training schedules. ${ }^{9,10}$ We are not aware of similar schemes in the United Kingdom. At the NUFC academy the principal preventative focus between the ages of 8 and 11 years is on the development of co-ordination, balance and body awareness. ${ }^{6}$ From 12 to 16 years, the range of joint movement and anthropometry is closely observed and recorded. Those footballers with delayed skeletal development are highlighted and specific attention is paid to training and conditioning so as to minimise the risk of injury. Beyond the age of 16 years, emphasis is placed on strengthening and endurance, with full-time training. Aerobic and anaerobic conditioning is also given equal importance.

There are legal implications for the management of musculoskeletal injury, and mismanagement may expose an academy and the treating clinician to malpractice claims. Significant injury, with the resulting loss of maximal potential function and earnings, exposes any professional club, the FA and the treating physician to the possibility of litigation, and this must be fully addressed by all parties concerned.

We are aware of reports of a marked increase in the incidence of sport-related musculoskeletal injury in childhood and adolescence, outside the setting of an academy. This is reflected in practice, where the first author (DJD) has performed over 25 reconstructive procedures for injuries to the anterior cruciate ligament in skeletally-immature children who have presented to Newcastle General Hospital Orthopaedic Unit in the last five years. This may also be a reflection of greater awareness of such injury and improved earlier diagnosis. Clearly, an academy environment and professional supervision, together with precautionary medical screening, can minimise the risk of adverse occurrences.

However, no such perceived trend in the wider community was seen in our group. We believe that this is because of a combination of close medical supervision, early investigation of injury, access to a regular physiotherapy review, and monitored age-specific training programmes. Such regimes have been developed in association with the FA Youth Training Scheme. It would be sensible to extend this knowledge to the local community through school education programmes. A number of premiership clubs, including NUFC, already offer community development schemes, but the main emphasis would appear to be on the acquisition of skills. We propose to extend these contacts to include the dissemination of knowledge on training and prevention of injury. We advocate subspecialisation of local orthopaedic services to cater for these sporting injuries. Emphasis should be placed on early diagnosis, counselling of the young athletic patient and their parents, facilities for early investigation such as fast-track MRI, and the involvement of educational resources where time off school may be required.

We wish to acknowledge the support of Newcastle United Football Club and the Football Association in the development of this study.

No benefits in any form have been received or will be received from a commercial party related directly or indirectly to the subject of this article.

\section{References}

1. Hawkins R, Fuller C. A prospective epidemiological study of injuries in four English professional football clubs. Br J Sports Med 1999;33:196-203.

2. http://news.bbc.co.uk/2/hi/business/4975632.stm (date last accessed 3 November 2006).

3. http://www.footballfoundation.org.uk/welcome (date last accessed 3 November 2006).

4. http://www.thefa.com/TheFA/SportsMedical-ExerciseScience/HealthProgrammes/ Postings/2003/11/20223.htm (date last accessed 3 November 2006)

5. Price RJ, Hawkins RD, Hulse MA, Hodson A. The Football Association medical research programme: an audit of injuries in academy youth football. Br J Sports Med 2004;38:466-71.

6. Adirim TA, Cheng TL. Overview of injuries in the young athlete. Sports Med 2003:33:75-81.

7. Duri ZA, Aichroth PM, Wilkins R, Jones J. Patellar tendonistis and anterior knee pain.Am K Knee Surg1999;12:99-108.

8. Flynn JM, Lou JE, Ganley TJ. Prevention of sports injuries in children. Curr Opin Pediatr 2002;14:719-22.

9. http://www.childrensmemorial.org/depts/sportsmedicine/program.asp (date last accessed 3 November 2006).

10. http://sportsmedicine.about.com/cs/knee_injuries/a/aa022202a.htm (date last accessed 3 November 2006). 